Claremont Colleges

Scholarship@ Claremont

Pomona Economics

Pomona Faculty Scholarship

$1-1-2019$

\title{
The Name Game: The Importance of Resourcefulness, Ruses, and Recall in Stock Ticker Symbols
}

\author{
Gary N. Smith \\ Pomona College \\ Naomi Baer \\ Pomona College \\ Erica Barry \\ Pomona College
}

\section{Recommended Citation}

Smith, Gary N.; Baer, Naomi; and Barry, Erica, "The Name Game: The Importance of Resourcefulness, Ruses, and Recall in Stock Ticker Symbols" (2019). Pomona Economics. 5.

https://scholarship.claremont.edu/pomona_fac_econ/5 


\title{
The Name Game: The Importance of Resourcefulness, Ruses, and Recall in Stock Ticker Symbols
}

\author{
Naomi Baer, Erica Barry, Gary Smith \\ Department of Economics \\ Pomona College \\ Claremont, California
}

Corresponding author:

Gary Smith

Department of Economics

Pomona College

425 N. College Avenue

Claremont CA 91711

gsmith@pomona.edu 
The Name Game: The Importance of Resourcefulness, Ruses, and Recall in Stock Ticker Symbols

\begin{abstract}
Previous research reported that a portfolio of stocks with clever ticker symbols outperformed the overall market by a significant margin during the years 1984 to 2005 . This paper reports the performance of those stocks during the subsequent years 2006 to 2018, and also investigates the 2006-2008 performance of a new set of clever-ticker stocks. Both clever-ticker portfolios beat the market by a substantial margin, supporting the resiliency of the clever-ticker phenomenon.
\end{abstract}

keywords: ticker symbols, efficient market hypothesis 
The Name Game: The Importance of Resourcefulness, Ruses, and Recall in Stock Ticker Symbols

A BABY, a GEEK, and a COW all walk into a bar looking for some BEER and VINO. What happens next? They all beat the market. Head, Smith, and Wilson (2009) (the "2009 Study") found that a portfolio of stocks with clever ticker symbols beat the market by a substantial margin during the years 1984 to 2005 .

We re-examine this surprising conclusion by updating the analysis for the subsequent years 2006 through 2018. In addition, we replicate its methodology with a new list of NASDAQ clever-ticker stocks.

\section{Background}

The notion that stock ticker symbols influence stock performance contradicts the semistrong form of the efficient-market hypothesis, which asserts that investors cannot use publicly available information to beat the market. In an efficient market with rational investors, stock prices should be based on anticipated cash flows and should not depend on something as superficial as ticker symbols. However, human decisions are often based on noisy data and flawed judgments (for example, Kahneman, Slovic, and Tversky 1982; DeBondt and Thaler 1995; Daniel, Hirshleifer, and Subrahmanyam 1998).

Our work contributes to a growing body of literature on the effects of ticker symbols on investment decisions. Jacobs and Hillert (2016) reported increased liquidity and trading volume for stocks with early-alphabet company names and ticker symbols. Itzkowitz, Itzkowitz, and Rothbort (2016) found that stocks with early-alphabet names and tickers are not only more 
liquid, but also more highly valued. Green and Jame (2013) report that the stocks of companies with fluent names have increased liquidity and higher market values, supporting the conclusion of Alter and Oppenheimer (2006) that pronounceable ticker symbols improved IPO performance. Similarly, Anderson and Larkin (2012) showed that when ticker symbols are actual words in the English language, their stock liquidity increases and Kadapakkam and Misra (2007) concluded that there is usually a stock-price decline after a company changes its ticker symbol. All of this research suggests that ticker symbols, which have nothing to do with the typical metrics used to evaluate companies, may affect stock trading and returns.

Although behavioral economics and neuroeconomics are relatively young fields, they offer a number of hypotheses that may help explain these phenomena. Memory involves the acquisition, storage, retention, and retrieval of information (D'Esposito and Postle 2015) and our understanding of human memory suggests that clever tickers may heighten investors' recall of companies. Horner, Bisby, Bush, Lin, and Burgess (2015) concluded that when humans encode memories, the separate elements that compose the memory are associated together via specific neurological mechanisms. If a ticker is easy to pronounce or clever, it is likely that the symbol invokes a sense of creativity and positivity when an investor reads or hears about it. This positive feeling - albeit completely unrelated to the success or relevant financial characteristics of the company - may then be implicitly associated with the stock when the investor recalls details about it. Thus, the recall of a clever ticker may lead the investor to have an irrationally positive and confident feeling that the company is a good investment. In addition, positive arousal has been shown to induce memory broadening effects that augment memory for peripheral details and increase the chance that investors remember other relevant investment information about 
companies (Yegiyan and Yonelinas 2011).

It has also been repeatedly demonstrated that experiences that elicit emotional arousal are remembered at higher rates than neutral experiences (Kensinger, 2009). In two studies examining the relationship between arousal and memory, researchers noted that participants subjected to enhanced emotional experiences exhibited greater long-term memories than control subjects who were exposed to neutral stimuli (Cahill and McGaugh, 1995; Kensinger and Corkin, 2003). Ticker symbols may invoke smaller emotional arousals than purposefully-crafted emotional stories, but this arousal-mediated enhancement has also been demonstrated to occur between individual words and when there are rapid changes between emotional and neutral stimuli (Anderson, Yamaguchi, Grabski and Lacka 2006). This implies that psychological effects could be induced by clever symbols, causing clever tickers to be more likely to be remembered than neutral tickers. Thus, the higher returns for clever-ticker stocks may be a combined consequence of two similar but distinct mechanisms: emotional memory enhancement causes investors to recall clever tickers at higher rates than neutral tickers, and the heightened positive association with clever tickers causes investors to consider them more attractive investments.

\section{Methods}

To determine whether the findings of the 2009 Study withstood the test of time, we extended The 2009 Study (which covered 1984-2005) to the subsequent years 2006-2018. The 2009 Study looked at 82 clever-ticker stocks for the years 1984 through 2005, using the Center for Research in Security Prices (CRSP) Permnos to track the daily returns for these stocks and for the CRSP market portfolio, in both cases including all dividends and other distributions. During these 22 years, some Permnos ended because of buyouts, mergers, bankruptcies, or other reasons and 
other Permnos appeared as stocks became publicly traded. The clever-ticker portfolio began with 17 stocks on the first trading day of January 1984 and ended with the 22 stocks shown in Table 1 on the last trading day of December 2005. We compared the daily returns for these 22 stocks with the daily returns for the CRSP market portfolio for the subsequent years 2006-2018. As in the original 2009 Study, taxes and transaction costs were ignored for both the clever-ticker portfolio and for the CRSP market portfolio.

To investigate whether similar results might occur for a new list of clever-ticker stocks, we focused on NASDAQ-traded stocks, which historically use four-digit ticker symbols, in contrast to the NYSE and AMEX, which use three or fewer characters. To ensure consistency, we used the same definition as in the 2009 Study: a ticker symbol is clever if it is related to the company's business in a witty way that makes the symbol memorable to investors. Two examples are BDAY (Celebrate Express Inc.) and SEED (Origin Agritech Limited).

Following the methods employed in the 2009 Study, we used the CRSP database to collect approximately 13,000 ticker symbols for companies traded on the NASDAQ at any point between 2006 and 2018. From this list of tickers, two of the authors independently examined every symbol and noted tickers that might be considered clever and memorable. Clever tickers included symbols such as PZZA and WIFI, respective tickers for Papa John's Pizza and Boingo Wireless. Eighty-seven percent of our selections coincided. The matched tickers in the two lists were then merged into a single list that excluded tickers that were just abbreviations of a company's name. After compiling the final list of 69 tickers, an online survey of people with little knowledge of the stock market was created that included a list of the 69 tickers and their company names, and the following instructions: 
Stocks are traded using ticker symbols. Some are simply the company's name (GM, IBM); some are recognizable abbreviations of the company's name (MSFT for Microsoft, $\mathrm{CSCO}$ for $\mathrm{Cisco}$ ); and some are unpronounceable abbreviations (BZH for Beazer Homes, PXG for Phoenix Footwear Group). Some companies choose symbols that are cleverly related to the company's business; for example, a company making soccer equipment might choose GOAL; an Internet dating service might choose LOVE. From the list below of ticker symbols, please select 10 that are the cleverest, cutest, and most memorable.

We received 237 responses. The 20 tickers with the most votes are listed in Table 2 and were used for our analysis. For each trading day from the beginning of 2006 to the end of 2018, we calculated the daily return for an equally weighted portfolio of these clever-ticker stocks. As time passed, some clever-ticker stocks stopped trading for a variety of reasons (such as bankruptcy, merger, or buyout) and other clever-ticker stocks entered the CRSP database. The comparison portfolio consisted of the stocks in the NASDAQ portfolio constructed by CRSP, which also had additions and deletions over time as stocks entered and left the market portfolio.

\section{Results}

We examined the daily returns for the 22 existing stocks from the 2009 Study from the beginning of 2006 until the end of 2018. Table 3 shows the mean and standard deviation of the daily returns for the clever-ticker portfolio and for the CRSP market portfolio for both the initial 22-year period and for the subsequent 13 years. The t-values and two-sided p-values are for a matched-pair t-test of the null hypothesis that the average difference is zero. 
As was true for the original 22 years, 1984 to 2005, the clever-ticker portfolio outperformed the CRSP market portfolio by a substantial margin for the subsequent 13 years, 2006 to 2018 . Figure 1 shows that, starting with $\$ 1$ on the first trading day in 2006 , the market portfolio grew to $\$ 1.863$ at the end of 2018 , a 4.90 percent compounded annual return, while the clever-ticker portfolio grew to $\$ 5.027$, a 13.22 percent compound annual return. Figure 2 compares the relative sizes of the clever-ticker portfolio and the CRSP market portfolio. The two portfolios had comparable returns from 2006 through the financial crisis of 2007 to 2008, but the clever-ticker portfolio strongly outperformed the CRSP portfolio beginning in 2009 and continuing to the end of the sample period.

The superior performance of the clever-ticker portfolio was not due to the outstanding performance of a few stocks: 19 of the 22 clever-ticker stocks did better than the overall market. If each of the 22 clever-ticker stocks had an independent 0.50 probability of beating the market, the probability that more than 18 would do so is only 0.00043 .

We investigated whether these excess returns could be explained by the Fama-French (1992, 1993) four-factor model,

$$
\mathrm{R}=\alpha+\beta_{1} \mathrm{MKT}+\beta_{2} \mathrm{SMB}+\beta_{3} \mathrm{HML}+\beta_{4} \mathrm{UMD}+\varepsilon
$$

where

$\mathrm{R}=\quad$ return on clever-ticker portfolio minus the return on Treasury bills

$\mathrm{MKT}=$ return on CRSP portfolio minus the return on Treasury bills

$\mathrm{SMB}=$ average return on three small-stock portfolios minus the average return on three large-stock portfolios (size factor) 
$\mathrm{HML}=$ the average return on two value portfolios minus the average return on two growth portfolios (book-to-market factor)

$\mathrm{UMD}=$ average return on two high prior return portfolios minus the average return on two low prior return portfolios (momentum factor)

Table 4 shows that the clever-ticker portfolio had substantial positive alpha for both the initial 22-year period and the subsequent 13-year period, though the latter alpha is not quite statistically significant at the 5 percent level $(p=0.075)$, against perhaps due to the substantially smaller sample size. The last column shows the differences between the coefficient estimates in these two periods and the t-values for a test of the null hypotheses that there are no differences. The difference between the two alpha values is not statistically significant $(p=0.30)$. The differences between the estimated coefficients of three of the four Fama-French factors are significant at the 5 percent level, which is not surprising since the composition of the cleverticker portfolio changed over time as clever ticker stocks came and went.

The new clever-ticker portfolio also beat the market, though not by as much as the original clever-ticker portfolio, either in the original sample period or the subsequent period. The difference between the daily returns on the new clever-ticker portfolio and the market portfolio had a mean of 0.000182 and standard deviation of $0.011492(2$-sided $p$-value $=0.347)$. Thirteen of the twenty new clever-ticker stocks did better than the market, while seven did worse, and the compound annual return was 11.27 percent, compared to the market portfolio's 4.90 percent. The Fama-French four factor model estimates are in Table 5. The alpha is again substantial and positive, though not statistically significant at the 5 percent level.

\section{Discussion}


We considered: (1) whether the clever-ticker stocks analyzed in the 2009 Study continued to do well over the subsequent 13 years; and (2) whether a new collection of clever-ticker stocks would also do well. Our results were consistent with the 2009 Study as the original clever-ticker stocks and 20 new clever-ticker stocks did better than the overall market.

The fact that the original tickers continued to outperform the market over the course of 35 years contradicts the claim that clever tickers outperform the market in the short run, but not in the long run (Zweig 2007). The positive excess returns could not be explained away by the Fama-French 4-factor model and, overall, 32 of the 42 clever-ticker stocks beat the market (2sided $\mathrm{p}=0.00094)$

Although we intentionally excluded seasoned investors from our survey, the participants may have been influenced by a familiarity with the companies. For example, Papa John's Pizza (PZZA) received the most votes (125), while Allscripts Healthcare Solutions Inc. (MDRX) only received 4 votes. However, most of the tickers that were selected by the survey participants were for relatively obscure companies.

\section{Conclusion}

In recent years, many companies have chosen clever ticker symbols. On average, the tickers identified as the cleverest have outperformed the market by a substantial margin. We demonstrate the resiliency of this phenomenon with respect to both the original clever-ticker stocks and a more recent set of clever-tickler NASDAQ stocks, a phenomenon that strongly contradicts the efficient market hypothesis.

The long-run superior performance of the original clever-ticker stocks suggests that clever tickers are not just short-term gimmicks. An appealing explanation is that the enhanced 
memorability and positive salience of clever tickers contributes to disproportionally high recall rates and confidence from investors. 
Table 1: Clever Ticker Portfolio at the End of 2005

\begin{tabular}{|c|c|c|}
\hline BABY & Natus Medical & medical products for babies \\
\hline BID & Sotheby's Holdings & auctions \\
\hline BUD & Anheuser Busch & Budweiser beer \\
\hline BOOM & Explosive Fabricators & explosives \\
\hline BTU & Peabody Energy Corp & coal \\
\hline CASH & Comdata Network & ATM networks \\
\hline CAKE & Cheesecake Factory & restaurant and dessert chain \\
\hline CHIC & Charlotte Russe Holding & teeny-bopper clothing \\
\hline DNA & Genentech & gene research \\
\hline FUN & Cedar Fair L P & amusement parks \\
\hline GAIT & Langen Biomechanics Group & orthotics products company \\
\hline GRIN & Grand Toys International & toy manufacturer \\
\hline GRR & Asia Tigers Fund & closed-end investment company \\
\hline JOB & General Employment Entrepreneurs & employment \\
\hline LENS & Concord Camera Corporation & cameras \\
\hline LUV & Southwest Airlines & low-fare airline \\
\hline POPS & National Beverage Corp & beverages \\
\hline ROCK & Gibraltar Industries & metal processing (Rock of Gibraltar) \\
\hline TUTR & Plato Learning & computer and Web-based instruction \\
\hline TINY & Harris \& Harris Group & venture capital in tiny technology \\
\hline WOOF & VCA Antech & veterinary services \\
\hline YUM & Tricon Global Restaurants & quick-service restaurants \\
\hline
\end{tabular}


Table 2: NASDAQ Clever Ticker Portfolio. Top 20 tickers with votes in parenthesis:

\begin{tabular}{|c|c|c|}
\hline PZZA (125) & Papa John’s Pizza & pizza restaurant franchise \\
\hline WIFI (121) & Boingo Wireless & mobile internet access \\
\hline ZEUS (102) & Olympic Steel Inc. & steel processor bonding \\
\hline BAGL (93) & Einstein Bros. Bagels & bagel and coffee chain \\
\hline OINK (85) & Tianli Agritech Inc. & hog farming \\
\hline KOOL (67) & Thermogenesis Corp. & bio-tech \\
\hline LAVA (65) & Magma Design Automation & software \\
\hline BOOM (64) & Dynamic Materials Corp & explosives \\
\hline TUSK (62) & Mammoth Energy Services & construction and energy services \\
\hline LENS (58) & Concord Camera Corp. & camera manufacturer \\
\hline BDAY (53) & Celebrate Express Inc. & online party supplies retailer \\
\hline SHOO (53) & Madden Steven Ltd. & shoe manufacturer \\
\hline SAVE $(50)$ & Spirit Airlines & budget airline \\
\hline PETS (50) & PetMed Express Inc. & online pet pharmacy \\
\hline WATT (49) & Energous Corp. & wireless charging technology \\
\hline SEED (48) & Origin Agritech Limited & agricultural technology \\
\hline SALE (45) & RetailMeNot, Inc. & coupon websites \\
\hline EYES (45) & Second Sight Medical Inc. & prosthetics for the blind \\
\hline XRAY (45) & Dentsply Sirona & dental equipment \\
\hline CHIC (39) & Charlotte Russe Holding Inc. & women's fashion brand \\
\hline
\end{tabular}


Table 3 Original Clever Tickers Daily Returns

1984-2005

$(\mathrm{n}=5552)$

Clever-Ticker Portfolio

Mean

Standard Deviation

Market Portfolio

Mean

Standard Deviation

Difference

Mean

Standard Deviation

t-value

Two-sided p-value
0.000918

0.000607

0.01269

0.015054

$(\mathrm{n}=3271)$
2006-2018$$
0.015054
$$

0.000499

0.000350

0.009788

0.012132

0.000257

0.011739

0.009114

2.66

1.61

0.0079

0.1074 
Table 4 Original Tickers, Estimates of a Four-Factor Model

$\begin{array}{lccc} & 1984-2005 & 2006-2018 & \text { Difference } \\ \text { Number of Observations } & 5552 & 3271 & \\ \text { Alpha } & 0.00049 & 0.00026 & -0.00023 \\ & (3.45) & (1.78) & (1.04) \\ \text { MKT } & 0.81 & 0.88 & 0.07 \\ & (39.52) & (64.56) & (2.85) \\ \text { SMB } & 0.64 & 0.56 & -0.09 \\ & (22.96) & (20.82) & (2.15) \\ \text { HML } & 0.28 & 0.17 & -0.11 \\ & (7.48) & (5.97) & (2.29) \\ \text { UMD } & -0.10 & -0.10 & 0.00 \\ & (4.56) & (5.11) & (0.02) \\ \text { Adjusted R-squared } & 0.29 & & 0.47 \\ \text { t-values } & & 0.68 & \end{array}$


Table 5 New Clever Tickers, Estimates of a Four-Factor Model

$\begin{array}{lc}\text { Alpha } & 0.00019 \\ & (1.10) \\ & \\ \text { MKT } & 0.91 \\ & (55.68) \\ \text { SMB } & 0.88 \\ & (27.64) \\ \text { HML } & 0.11 \\ & (3.24) \\ \text { UMD } & -0.13 \\ & (5.80) \\ \text { Adjusted R-squared } & 0.62\end{array}$

( ): t-values 


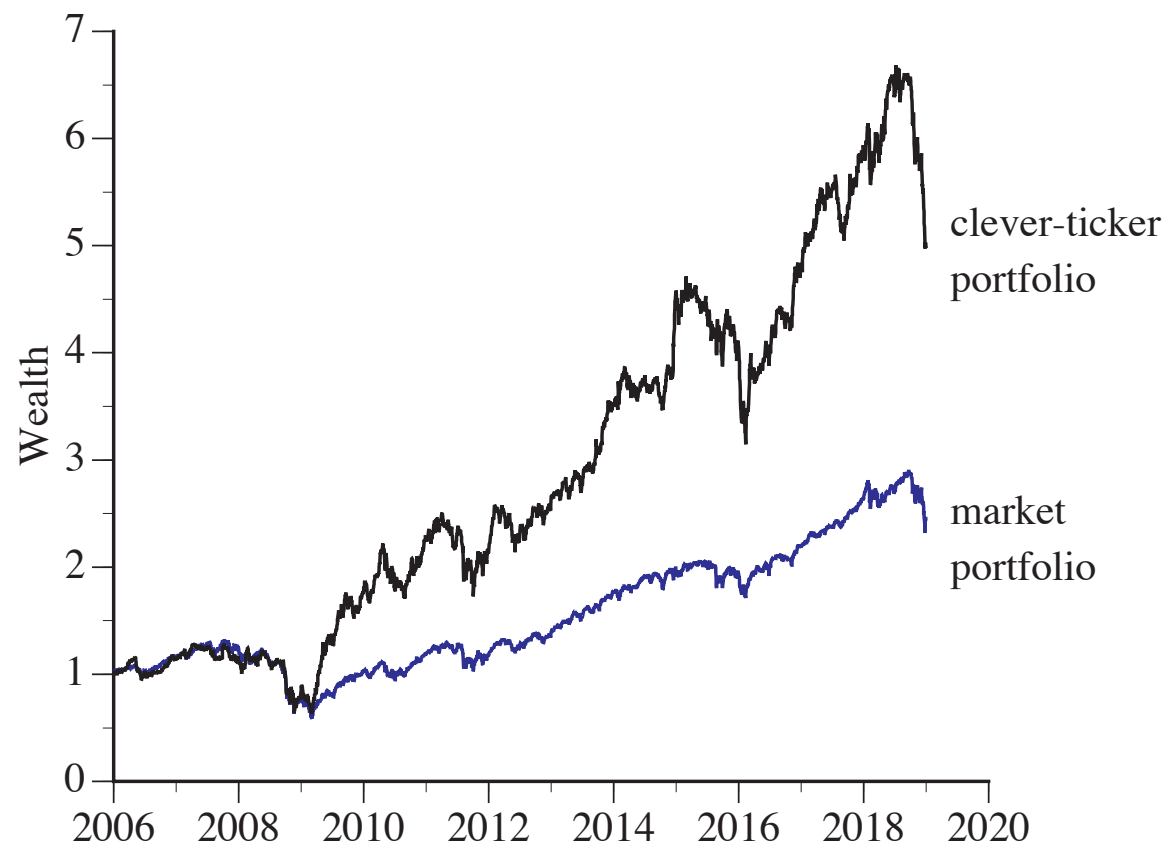

Figure 1 Original Clever-Ticker Portfolio and Market Portfolio 


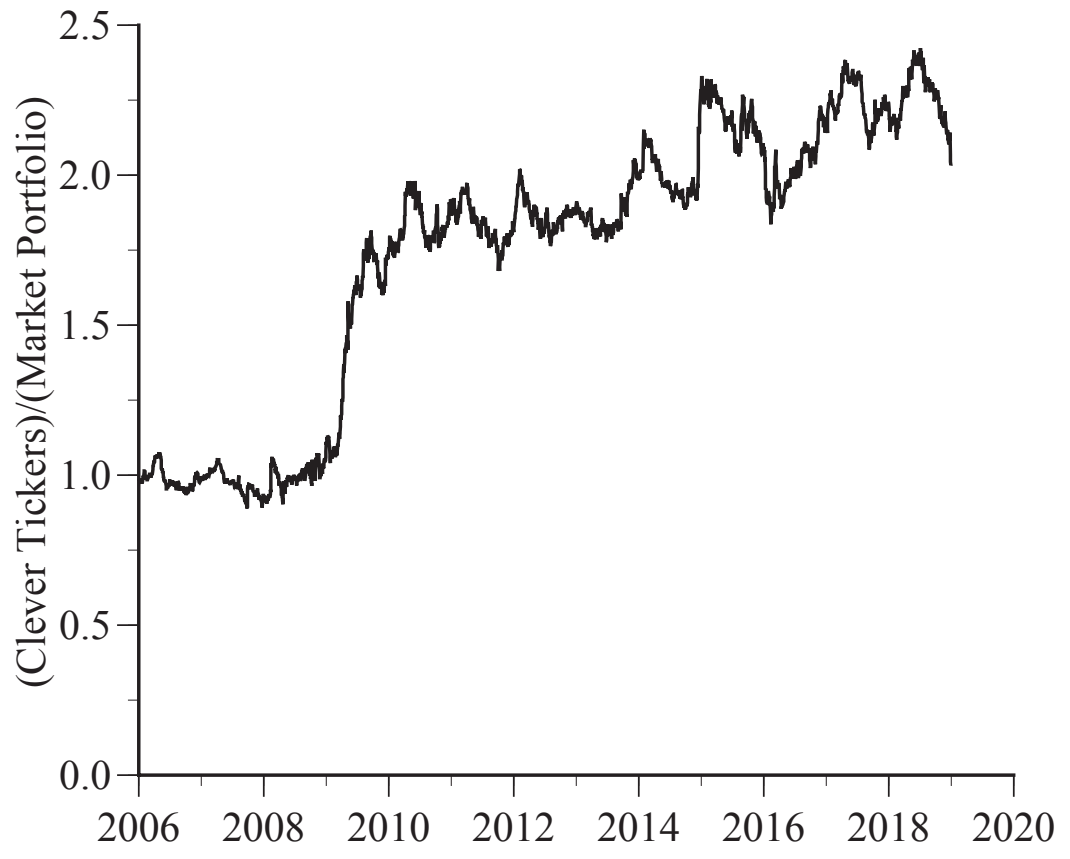

Figure 2 Original Clever-Ticker Portfolio Relative to Market Portfolio 


\section{References}

Alter, A. L., \& Oppenheimer, D. M. 2006. Predicting short-term stock fluctuations by using processing fluency, Proceedings of the National Academy of Sciences, 103(24), 9369-9372.

Anderson, A. G., \& Larkin, Y. 2018. Does Non-Informative Text Affect Investor Behavior? SSRN Scholarly Paper No. ID 2181195.

Anderson, A. K., Yamaguchi, Y., Grabski, W., \& Lacka, D. 2006. Emotional memories are not all created equal: evidence for selective memory enhancement. Learning \& Memory, 13(6), $711-718$.

Cahill, L., \& McGaugh, J. L. 1995. A novel demonstration of enhanced memory associated with emotional arousal. Consciousness and Cognition, 4(4), 410-421.

Daniel, K., Hirshleifer, D., \& Subrahmanyam, A. 1998. Investor Psychology and Security Market Under- and Overreactions. The Journal of Finance, 53(6), 1839-1885.

DeBondt Werner F. M., Thaler, Richard H. 1995, Financial decision-making in markets and firms: A behavioral perspective; in Robert A. Jarrow, Voijslav Maksimovic, and William T. Ziemba, eds.: Finance, Handbooks in Operations Research and Management Science 9, Amsterdam: North Holland, 385-410.

D’Esposito, M., \& Postle, B. R. 2015. The cognitive neuroscience of working memory, Annual Review of Psychology, 66, 115-142.

Durham, Greg, \& Santhanakrishnan, Mukunthan 2016. Do Fluent Tickers Appeal to Investor Sentiment?, The Quarterly Review of Economics and Finance, 61(C), 89-96

Egginton, Jared \& Van Ness, Bonnie \& Van Ness, Robert 2009. Does it Matter if Ticker Symbols are 3 or 4 Characters on NASDAQ?. SSRN Electronic Journal. 10.2139/ssrn.1448119. 
Fama, E. F., \& French, K. R. 1992. The cross-section of expected stock returns, Journal of Finance, 47(2), 427-465.

Fama, E. F., \& French, K. R. 1993. Common risk factors in the returns on bonds and stocks, Journal of Financial Economics, 33(1), 3-53.

Green, T. C., Jame,. R. 2013. Company name fluency, investor recognition, and firm value, Journal of Financial Economics, 109(3), 813-834.

Head, Alex, Smith, Gary, \& Wilson, Julia 2009. Would a stock by any other ticker smell as sweet? The Quarterly Review of Economics and Finance, 49(2), 551-561.

Horner, A. J., Bisby, J. A., Bush, D., Lin, W.-J., \& Burgess, N. 2015. Evidence for holistic episodic recollection via hippocampal pattern completion. Nature Communications, 6, 7462.

Itzkowitz, Jennifer, Itzkowitz, Jesse, \& Rothbort, Scott 2016. ABCs of trading: Behavioral biases affect stock turnover and value. Review of Finance, 20(2), 663-692.

Jacobs, Heiko, and Hillert, Alexander 2016. Alphabetic Bias, Investor Recognition, and Trading Behavior, Review of Finance, 20(2), 693-723

Kahneman, Daniel, Slovic, Paul, and Tversky (eds.) 1982. Judgment Under Uncertainty: Heuristics and Biases, Cambridge: Cambridge University Press.

Kadapakkam, P.-R., \& Misra, L. 2007. What's in a nickname? Price and volume effects off a pure ticker symbol change, Journal of Financial Research, 30(1), 53-71.

Kensinger, E. A. 2009. Remembering the Details: Effects of Emotion. Emotion Review, 1(2), 99-113. https://doi.org/10.1177/1754073908100432

Kensinger, E. A., \& Corkin, S. 2003. Memory enhancement for emotional words: are emotional 
words more vividly remembered than neutral words? Memory \& Cognition, 31(8), 1169-1180.

Kensinger, E. A., \& Corkin, S. 2003. Memory enhancement for emotional words: Are emotional words more vividly remembered than neutral words? Memory \& Cognition, 31(8), 1169-1180.

Li, Xiaodi, Mahani, Reza S., and Sandhya, Vallapuzha 2011. Does Investor Attention Affect Stock Prices?Available at SSRN: $\underline{\text { https://ssrn.com/abstract=1748851 or http://dx.doi.org/ }}$ $\underline{10.2139 / \text { ssrn. } 1748851}$

Yegiyan, N. S., \& Yonelinas, A. P. 2011. Encoding details: Positive emotion leads to memory broadening. Cognition and Emotion, 25(7), 1255-1262.

Zweig, Jason 2007. Your Money and Your Brain: How the New Science of Neuroeconomics Can Help Make You Rich. New York: Simon and Schuster. 